\title{
The Integration of Marketing Problem-Solving Modes and Marketing Management Support Systems
}

To be effective, decision aids for marketing managers should match with the thinking and reasoning processes of the marketing decision makers who use them. The authors take a cognitive approach to problem solving in marketing. They develop a classification of "marketing problem-solving modes" and distinguish four modes: optimizing, reasoning, analogizing, and creating. They also present a typology of what they call "marketing management support systems." In an integrating framework, they then link the four marketing problem-solving modes with the most appropriate marketing management support systems. The authors conclude with a discussion of the implications of this "demand-side" approach to marketing management support systems.

$\mathbf{T}$ here is an increasing need for tools that assist marketing decision makers in carrying out their tasks. Because of the proliferation of products and brands, ever larger numbers of market segments, fierceness of competition, and overall acceleration of change, marketing decision situations have become complex, and decisions must be made under increasing time pressure. The "marketing information revolution" produces enormous amounts of data. Yet these data must be transformed and combined with knowl edge about the marketing decision situation before the marketing manager can use the information for decision making. Developments in statistics, model building, knowledge engineering, and information technology have resulted in a rich collection of such support tools for marketing managers. These tools are intended to support the problem-solving efforts of a marketing manager. Therefore, to be successful, they should match with the thinking and reasoning processes of the manager. For this reason, we take the marketing decision maker's decision process as the starting point. We consider the marketing decision maker as a problem solver and discuss the cognitive models that describe the different ways a marketer goes about solving problems. Marketing decision makers must design and execute marketing programs for products or brands. Usually they bring a substantial amount of knowledge-from experience and expertise - to bear on solving a particular marketing problem. Furthermore, they are confronted with a constant stream of information about the market and the position of

Berend Wierenga is Professor of Marketing and Gerrit $\mathrm{H}$. van Bruggen is Assistant Professor of Marketing, Department of Marketing Management, Center for Information Technology in Marketing (C/IT/M), Rotterdam School of Management, Erasmus University Rotterdam. The authors thank Arco Dalebout, Soumitra Dutta, Jehoshua Elishberg, John Rossiter, Ale Smidts, and three anonymous reviewers for their thoughtful comments on earlier versions of this article. products-both formal data and informal cues about customers, distributors, competitors, and so forth.

The basic questions we address are the following: (1) How does the mind of a marketing decision maker combine and process all the elements of information and knowledge to arrive at decisions? and (2) What does this imply for the required characteristics of effective marketing support tools? We introduce the concept of marketing problem-solving modes (MPSMs). An MPSM characterizes the problem-solving process of a marketer. Different marketing decision makers can use different MPSMs. And the same decision maker can use different modes at different times. The required type of support depends on the MPSM employed by a decision maker. The concept of MPSM introduces a demand-side perspective to marketing support systems. Discussions about support tools, thus far, often have taken a supply-side approach, emphasizing their features and capabilities rather than the conditions under which they are appropriate.

On the supply side, we deal with the systems that are available to support a marketing decision maker. Today we have marketing information systems (MKISs), marketing decision support systems (MDSSs), marketing knowledgebased systems (MKBSs), marketing expert systems (MESs), and so on. We use the term marketing management support systems (MMSSs) to refer to this set of tools as a whole. We identify the specific characteristics and capabilities of the various types of MMSSs to determine the appropriate MMSS for a specific problem.

Our goals follow:

1. To develop a classification of MPSMs that is based on different cognitive models of the way a marketing manager solves a problem. For reasons we explain subsequently, we refer to this as the "ORAC classification."

2. To develop a classification of MMSSs that is based on distinguishing characteristics and capabilities that are relevant for assigning MMSSs to the different MPSMs they must support. 
3. To match the classification of MPSMs with that of MMSSs and develop an integrating framework that can be used to explain the evolution and use of MMSSs over time and to generate issues for further research into MMSS.

We start with a classification of MPSMs. We define four MPSMs—optimizing, reasoning, analogizing, and creating (hence the acronym ORAC) - and briefly deal with the antecedents of these MPSMs (i.e., the conditions under which each of them is most likely to occur). Next, we describe the different types of MMSSs in terms of their constituent components and the kind of support each of them best provides (capabilities and functionalities). Finally, we connect the support requirements of the various MPSMs with the characteristic features of the different MMSSs. This results in an integrating framework that puts the main issues of this article into perspective.

\section{The ORAC Classification of MPSMs}

In this section we present a typology of MPSMs. We distinguish four different modes: optimizing, reasoning, analogizing, and creating. These four MPSMs are ordered from hard optimization by means of exact calculations to soft associations and creativity.

\section{Optimizing}

Marketing operations are one of the last phases of business management to come under scientific scrutiny (Kotler 1971, p. 1).

The cognitive model of a marketing manager using the optimizing mode is that of a scientist or engineer who has a clear insight into how processes work. This is represented by a mathematical model, which describes the relationships between the relevant variables in a quantitative way. The decision maker searches for those values of the decision variables that maximize the goal variable(s) for the particular problem. These optimal values for the decision variables are determined in the "model world." Next, they are translated into the "real world." A marketing management problem is converted into a "marketing programming problem" (Kotler 1971, Ch. 1). The model-building tradition became a prominent school in marketing (science). The impressive achievements of the model-building tradition in marketing have been put on record in a series of books that appeared in intervals of about a decade: Kotler (1971), Lilien and Kotler (1983), and Lilien, Kotler, and Moorthy (1992). Also, a recent volume edited by Eliashberg and Lilien (1993) pays tribute to the extensive work in marketing models.

For an overall marketing optimization-that is, where all marketing instruments are optimized simultaneouslywe would need a "comprehensive marketing system," specifying all the relevant variables and their mutual relationships (Kotler 1971, p. 667). Although efforts have been made to specify relationships between and within all the subsystems of a comprehensive marketing system (e.g., BRANDAID; Little 1975), a much more easily achieved goal is to determine the optimum for one marketing instrument or at most a part of the marketing program. One of the first examples of a "partially" optimizing model is the MEDIAC model for media planning, developed by Little and Lodish (1969). The positive part of the MEDIAC model describes the relationship between the value of the exposure to an advertising campaign, as expressed by the planned insertions in the various media (i.e., a specific media plan). This model then can be used to find the optimal media plan, given the advertising budget on the one hand and the audience and cost data of the available media on the other.

The following example illustrates marketing problem solving in the optimizing mode:

At Syntex Laboratories, a pharmaceutical company in the U.S., management was uneasy about the size of the sales force and its allocation over products and market segments. The sales force had increased every year in an adhoc way. The senior vice-president for sales and marketing felt that there was a better way to determine the size of the sales force needed to optimally support the sales of the company's products. Two management scientists were asked to implement such an optimization approach. Models were developed that described the relationship between sales effort and sales for the various categories of drugs in the different market segments. These models were then used in a stepwise optimization procedure, where each additional amount of sales capacity was allocated to the most profitable product/segment. Based on this approach the corporation significantly increased its sales force size and changed its deployment. This resulted in a documented continuing $\$ 25,000,000$, eight percent annual sales increase, with a return on the sales force increase of at least 100 percent (Lodish et al. 1988).

\section{Reasoning}

Human beings translate external events into internal models and reason by manipulating these symbolic representations (Craik 1943, p. 5I).

The fact that people form and use mental representations of phenomena in the outside world long has been recognized. Such representations are called mental models. Mental models are symbolic structures, a representation of a body of knowledge in the human mind (Johnson-Laird 1989). A person can use such a mental model for reasoning about a phenomenon. In cognitive science this type of approach to a problem is called "model-based reasoning" (Forbus 1988; Johnson-Laird 1989). Mental models have generated considerable interest, and the concept has been used in different domains, sometimes at the fundamental level of human perception-for example, the mental representation of a word, a geometric figure, or language comprehension (Anderson 1983; Johnson-Laird 1988)-but also to describe how humans deal mentally with complex phenomena. Examples are mental models for physical systems such as the working of a calculator (Gentner and Stevens 1983), mental models that underlie public policy decisions (Axelrod 1976), managerial mental models (Courtney, Paradice, and Mohammed 1987), and mental models as a basis for strategic planning and subjective forecasting (Klayman and Schoemaker 1993). In the optimizing mode it is assumed that there is an objective model that provides a valid description of the marketing phenomenon under study.

However, only a small part of all marketing phenomena has been brought under scientific scrutiny, and our system- 
atic, scientifically based knowledge of marketing phenomena is limited. So if a systematic world underlying marketing phenomena exists at all, it has been explored and mapped out only partially. In the absence of an objective model, a marketer often adopts an MPSM called reasoning. In the reasoning mode, decision makers construct a representation of the marketing phenomenon in their minds. These mental models are the basis for the manager's reasoning about the problem. A mental model consists of variables deemed relevant and the supposed cause-and-effect relationships among these variables. It helps a decision maker to diagnose and solve a specific problem. Different marketing managers can have different mental models with respect to the same phenomenon. For example, in the case of advertising, different marketing managers may use different models to explain why a particular advertising campaign was successful.

Mental models tend to be qualitative, subjective, and incomplete. Mental models can be at variance with reality. In physics many examples exist of mental models that proved to be wrong after thorough scientific examination. For example, the idea that heat and temperature are the same concept existed among scientists for centuries and was replaced by the correct model only around 1750 (Wiser and Carey 1983). Although mental models might not always be correct, they are useful because they offer the marketer a framework for interpreting and reasoning about marketing problems and their solutions.

An example of a manager following the reasoning mode follows:

It's November 1995, and Dirk Jansen, product manager of a traditional margarine brand in the Dutch edible fats market called Landlord, has just received the new four-week Nielsen figures, which refer to period 10 , ending beginning of October. These figures show that Landlord's market share in period 10 is $8.4 \%$, down from $10.7 \%$ in the last period. This drop is quite alarming, and Dirk starts to think about possible causes. His first idea, that the fall in market share is just an occasional incident, is dismissed immediately, because there has been a continuous decrease since period 5 (May), when Landlord's market share was still 12.4\%. According to Dirk's view (mental model), the Dutch edible fats market can be divided into "standard brands" and "diet brands." He suspects that the market share of Landlord, which belongs to the standard-brands category, is going down as a consequence of the decrease of the share of standard brands in the total market. (This share went down from $73 \%$ in 1992 to $67 \%$ in 1994.) However, a look at the Nielsen figures shows that from period 9 to period 10 , the share of standard brands did not decrease further; it even slightly increased. Within standard brands, Landlord's drop in market share is even more dramatic than for the whole market (from $16.2 \%$ to $12.5 \%)$. A check of distribution trends shows that weighted distribution is (only) $81 \%$ and that distribution of Landlord is down in four of the five major retail chains. In the one chain where the distribution increased, market share of Landlord also went up. Following this cue, Dirk next looks at price levels and quickly finds out that, whereas the average price of the brands in the market went down $2 \%$ from period 9 to period 10, Landlord's price went up $3 \%$. Duchess, a competing brand, has lowered its price and saw its market share increase $18 \%$. Following this lead, Dirk next looks at display share. (Inspired by a real-life market situation and actual figures, though the product category and brand names have been disguised.)

It is clear that this product manager is guided by a mental model of marketing phenomena, which contains elements such as random versus systematic changes, the possibility of different demand in different market segments, and elements of the marketing mix such as distribution and price.

\section{Analogizing}

An individual's knowledge is the collection of experiences that he [or she] has had or that he [or she] has heard about (Riesbeck and Schank 1989, p. 7).

When confronted with a problem, a person has a natural inclination to bring to bear the experience gained from solving similar problems, or to analogize. A doctor, faced with a patient who has an unusual combination of symptoms, could remember another patient with similar symptoms and propose the same diagnosis as in the previous case (Kolodner 1993). Analogizing is considered a fundamental mechanism in human understanding and problem solving. "Analogymaking lies at the heart of intelligence" (Hofstadter 1995, p. 63). Children automatically apply analogical thinking, and some elements of analogical thinking can be found even in apes and chimpanzees (Holyak and Thagard 1995).

For a long time the "general problem-solving" school was dominant in cognitive science. According to this school, human thought depends on a set of reasoning principles that are independent of any given domain-meaning that human beings reason the same way no matter what they are reasoning on. Simon (1979, p. xii) formulates this standard way of operating by "Thinking Man" as follows: "Thinking is a process of serial selective search through large spaces of alternatives guided by individual mechanisms that operate through dynamically adapting aspiration levels."

The proponents of analogical reasoning have a very different view (Riesbeck and Schank 1989, p. 3): "Certain aspects of human thought may be a simpler affair than many scientists have imagined." In other words, human problemsolving behavior often can be explained by much simpler mechanisms than the general problem solver idea. Analogical (or "cased-based") reasoning implies that the original concrete instances are used for reasoning, rather than abstractions that are based on those instances. We might deduce general principles from the experienced cases, but according to Riesbeck and Schank (1989, p. 7), such "general principles are impoverished compared to the original experience." After many repetitions of the same situation, some cases could "coalesce" into rules. However, these rules are encoded in memory separate from any particular instance of their use or the history of their creation.

Wide support exists for analogical reasoning as a model for human decision making. Studies in human problem solving reveal the pervasiveness of analogy usage (Stemberg 1977). People find analogical reasoning to be a natural way to reason. It has been observed to be used by car mechanics, physicians, architects, and caterers. In particular, case-based reasoning excels as an approach to "weak-theory domains," domains where phenomena are not understood well enough 
to determine causality unambiguously (Kolodner 1993). Indeed, much of marketing problem solving probably follows the analogizing path. A marketing manager usually has a set of experiences (cases) available from memory, referring to all kinds of marketing events: new product introductions, price changes, sales promotions, advertising campaigns, reactions of competitors, and so on. In a new situation, even without active effort on the part of the manager, one or more earlier situations come to mind that resemble the current one. Sometimes, the manager will be inclined to choose the same kind of solution as in the previous case. For example, a manager could decide to execute the same sales promotion for a product in country $\mathrm{B}$ as the one that was so successful in country A earlier. However, in many cases the manager will not literally repeat the previous solution but will adapt it somewhat. In a sales promotion, for example, the specific premium and packaging used in country B could differ from those used in country $A$. Hoch and Schkade (1996) find that to arrive at a forecast, decision makers often search their experience for a situation similar to the one at hand and then make small adjustments to that previous situation. Basically, in these situations a process of analogizing or analogical reasoning takes place. For most problems, marketing theory is insufficient (weak-theory domain). Often, marketing managers also have no generalized rules, drawn from experience, available that could serve as elements of a mental model. However, managers do have a lot of experience with more or less similar cases. Moreover, in many instances there simply is not enough time to solve a problem by reasoning from "first principles"-that is, to build a mental model that explains a phenomenon in terms of elementary events. Analogical reasoning, then, is a fast and appropriate way of problem solving.

An example of a manager employing the analogizing mode follows:

Rob de Zwart, marketing director of Croky Chips, a subsidiary from United Biscuits in The Netherlands, was confronted with a drop in market share of Croky chips from $32 \%$ in March 1995 to $18.5 \%$ in the fall of the same year. The major cause of this dramatic decrease was the very successful Flippo campaign, launched by competitor Smith Chips in the Spring. Flippos are small round plastic discs, with Warner Bros.' cartoons on them, that are put into the bags with the chips. There are all kinds of different Flippos - for example, Regular, Game, Flying, Chester, and Techno Flippos (335 different types in all)and collecting and exchanging Flippos became a craze among children as well as teenagers and young adults. At the start of the Flippo campaign, Croky did not pay much attention. Flippos were thought to be too "childish," and Croky launched an infotainment campaign (trendy texts on chips bags) combined with discounts on CDs. When Croky realized that, against their expectations, the Flippos had really touched a chord with teenagers, they developed an analogous campaign, adapted from the "Flippo case." This Croky campaign, called "Topshots" instead of Flippos, also puts plastic discs into bags of chips. However, in the case of Topshots, the discs are not round but octagonal (the discs can be used to build all kinds of constructions), and they carry not Warner Bros.' cartoons but pictures of all (198) players in the highest league of the Dutch Soccer competition. This seems a clever adaptation: Soccer is by far the most popular sport in Holland and the European Championships were not far off. First indications are that the Topshots may reach the same level of popularity as Flippos (description of actual situation in The Netherlands).

A two-way transition exists between the analogizing mode and the reasoning mode. If a person attempts to use the reasoning mode and no adequate model can be found, he or she tends to resort to analogizing. "When a causal model fails to explain some phenomenon, a person is likely to search for a useful analogy, for example the model of a thermostat as a valve" (Johnson-Laird 1989, p. 487). Conversely, experience with many cases in a certain domain can result in the abstraction of rules that can become the building blocks of a mental model. The cases from which these rules were derived are no longer known. Riesbeck and Schank (1989) use the term "ossified cases" for this situation. An example of an ossified case in marketing is the general rule that the first brand in a product category has a pioneer premium and most likely will become the market leader: "It is better to be first, than it is to be better" (Ries and Trout 1993).

\section{Creating}

Few observers would disagree that there is a considerable amount of judgment and creativity, if not art, involved in being a successful marketing manager (Hulbert 1981, p. 19).

The last marketing problem-solving mode that we distinguish is creating. Using the creating mode, a marketing decision maker searches for concepts, solutions, or ideas that are novel in responding to a situation that has not occurred before. However, what precisely is a creative idea, and how do marketers hit upon those ideas that really make a difference in the marketplace? What was the creative process that led to successes like Post-it ${ }^{\circledR}$, the famous yellow pieces of paper from $3 \mathrm{M}$, or the catchy brand name Q8, of Kuwait Petroleum? The literal (dictionary) meaning of create is "to bring into being or form out of nothing." Ackoff and Vergara (1981, p. 8) define creativity (in a management context) as "the ability to break through constraints imposed by habit and tradition so as to find new solutions to problems." This formulation makes clear that creating means stepping away from the conventional path. Creativity implies "divergent thinking"- that is, thinking with an open mind, expanding the set of decision possibilities, enlarging the solution space-which is the opposite of "convergent thinking" - that is, the evaluation and screening of existing possibilities (Chung 1987). This divergent thinking also has been referred to as "restructuring the whole situation" (Wertheimer 1959), "reframing" (Russo and Schoemaker 1990), and "transformation of conceptual spaces" (Boden 1991). However, divergent thinking is not a sufficient condition to explain creativity. The element of problem finding. problem discovery, or "sensing gaps" is also important (Kabanoff and Rossiter 1994). Creativity often means coming up with solutions for problems of which a person was not aware. Creativity involves combining known but previously unrelated facts and ideas in such a way that new ones emerge (Elam and Mead 1990). Creativity also can be 
described as the mapping, exploration, and transformation of structured conceptual spaces (Boden 1994). An important element of creativity is "making connections" (MacCrimmon and Wagner 1994). This means the creation of new ideas through the association of existing ones.

It is widely accepted that marketing requires a good deal of creativity. Marketing problems often are not well defined in terms of goals, means, mechanisms, and constraints, and often do not lend themselves to the procedural or logical reasoning in conventional computer programs or knowledgebased systems. The cognitive model of a marketer following the creating mode is one of a decision maker who-consciously or unconsciously, by means of mapping, exploring, and transforming conceptual space, expanding the number of possible solutions through divergent thinking, and making connections and associations-is searching for novel and effective ideas and solutions to strengthen the market position of the product, brand, or company. Creating can refer to all aspects of the marketing management domain, including generating ideas for new products or services, innovative advertising or sales-promotion campaigns, new forms of distribution, and ingenious pricing. Creativity is an important asset. Many companies owe their existence to a creative new product or process, and creativity is often the means for survival as well as growth.

The following is an example of a manager successfully employing the creating mode:

In the seventies, when John Sculley was Vice-President of Marketing at Pepsi-Cola, this company was struggling way behind the number one in the industry, Coca-Cola. At Pepsi-Cola there was general agreement that the most important competitive advantage of Coca-Cola was its characteristic hourglass-shaped bottle. This design had almost become the product itself. It was pleasant to hold in the hand, easy to deal with in vending machines and had become as American as apple pie. People at Pepsi had spent millions of dollars and many years of research to come up with a bottle for Pepsi-Cola that could play the same role as the hourglass-shaped bottle did for CocaCola. However to no avail. Then, Sculley realized that Pepsi took the wrong approach to the problem. As long as they stayed within the solution space defined by Coca-Cola (i.e., find a competitive advantage through the shape of the bottle) it would be very hard to beat Coca-Cola. So Sculley ordered his people to take a fresh look at what people really do with cola. The consumption behavior of families was studied, that were allowed to order weekly quantities of cola as large as they wanted, against a discount price. It was discovered that these people always used up all their cola, irrespective of the quantities bought. So the purpose should be to have consumers take larger quantities of cola to their homes. Once they have it, they will consume it. This triggered the development of large size packages by Pepsi-Cola, which had a direct positive effect on their market share. Besides that, Coca-Cola could not transform its hourglass-shaped bottle to larger packages and consequently lost much of its advantage in the competitive battle under the new (large packages) rules. So by "restructuring the whole situation," Sculley created the basis for PepsiCola as a very strong competitor of Coca-Cola on the American market (Russo and Schoemaker 1990, pp. 8-10).

There can be some overlap between the creating and the analogizing modes. Analogies can be a source of creativity:
A metaphor can be a springboard for creative solutions (Tardif and Sternberg 1988) and can generate mental leaps (Holyak and Thagard 1995). However, the two modes differ in that in the analogizing mode, the search is for situations, as similar as possible, that the decision maker has already experienced or knows, whereas in the creating mode, the analogies that trigger the best ideas tend to be remote associations.

\section{Relationships Among MPSMs}

Three comments are in order on the relationships between and among the four MPSMs in our ORAC classification. The first is that the MPSMs are not mutually exclusive in the sense that a marketing decision maker can use only one mode for the solution of a particular problem. Some decision situations will call for two or more modes to be employed, sometimes in different phases of the solution process. We use the MPSMs here in the sense of the dominant mode - that is, for a particular marketing decision situation, the MPSM that describes that situation best or comes closest to what the manager actually does. For example, consider a marketer determining the size of an advertising budget. If the elements of primary consideration are the effect of advertising on awareness, the most likely advertising efforts of competitors, and the way market share will be affected by advertising, together with some (unquantified) notion that one should not overadvertise (i.e., beyond the point where marginal returns equal marginal costs), then the dominant problem-solving mode is reasoning, though there are elements of optimizing in this approach and maybe some analogizing. However, reasoning is the MPSM that describes this situation most adequately.

The second remark is a corollary of the first, that the four MPSMs are not completely separate from each other, in that a decision maker can switch from using one mode to using another. For example, when using the reasoning mode a marketer's mental model of a particular marketing situation becomes more refined and complete through observation and introspection. At some point this model could become sufficiently detailed and complete for the marketer to make a precise mathematical specification. When this mathematical model then is used for finding the best values for the marketing decision variables, a transition has occurred to the MPSM of optimizing. As mentioned previously, transitions also can occur between analogizing and reasoning. A person who has observed many cases in a specific domain can "generalize" from these cases and develop rules to reason with (Kolodner 1993).

Third, there is an order inherent in the ORAC classification: The optimizing mode is appropiate for solving highly structured problems, the reasoning mode for moderately or only somewhat structured problems, and so on down to the creating mode, which is appropriate for solving highly unstructured problems. Generally speaking, a problem that can be solved using a particular MPSM also can be solved using MPSMs that assume less structure. For example, a problem that has enough structure to be solved in the optimizing mode also can be approached using reasoning, analogizing, or creating. In general, however, a problem that 
is highly unstructured, which typically would require a creative problem-solving approach, cannot be solved using a mode that assumes more structure.

\section{Positioning of the ORAC Framework}

The ORAC framework presents a classification of the way marketing decision makers solve problems. Although the classification and the particular names of the four MPSMs are new, the development of the ORAC framework is based on conceptual and empirical research that has been carried out in cognitive psychology, cognitive science, decision theory, and management and organizational studies over the past several decades. The ORAC framework proposes that marketing management involves more than just the analytical approach to problem solving. In the psychological literature, two systems of reasoning are distinguished: reasoning through symbol manipulation and reasoning according to the "associative system" (Sloman 1996). (The word reasoning has a broader meaning here than in the sense of our reasoning mode.) Reasoning through symbolic manipulation (called "rule-based system" by Sloman) concentrates on causal, logical, and hierarchical relations and on hard constraints and can be characterized with expressions such as deliberation, explanation, formal analysis, and verification. The associative system of reasoning, conversely, is characterized by parallel processing of information, soft constraints, intuition, creativity, and associative memory. Our optimizing and, to a lesser extent, reasoning modes belong to the symbol-manipulation system, whereas our analogizing and creating modes take place under the associative reasoning system. The ORAC framework extends the perspective of marketing decision making from the analytical/explanatory mode to the associative/creative mode and incorporates the two main systems of human reasoning. Russo and Schoemaker (1990) develop a model for managerial decision making, in which the concept of framing is particularly interesting. Framing means marking the contours of the problem, defining what must be decided, and determining the evaluation criteria. Frames are powerful and determine the decision maker's perspective on a problem; they also constitute boundaries for the solution space. These boundaries are often implicit, because few people are fully aware of the decision frames (mental models) they have adopted (Russo and Schoemaker 1990, p. 20). The optimizing and, to a large extent, the reasoning modes operate within given frames and look for solutions that fit in those frames (convergent thinking). However, it is useful for a decision maker to challenge these frames from time to time and take a different perspective or approach to the problem. Such a process of reframing, which requires divergent and lateral thinking, takes place in the analogizing and creating modes.

In another approach to decision making, decision analysis, a decision tree is constructed, which represents the possible courses of action, and subsequently the subjective probabilities and utilities of the decision maker are measured (Raiffa 1968). The starting point of decision analysis is formulating the problem; beyond that, decision analysis is clearly a case of finding a solution within a given frame (convergent thinking). The purpose of a decision analysis is to find the decision that maximizes the expected subjective utility of the decision maker. Consequently, problem solving through decision analysis is an example of using the optimizing mode. For important marketing decisions, a decision maker might go through the elaborate procedures (see, e.g., Kleinmuntz 1990) of problem structuring, probability assessment, and risk attitude measurement that a decision analysis requires. However, we argue that in day-to-day marketing situations, most problems call for applying one of the other modes.

In the literature on managerial decision making, much attention is devoted to so-called sequence frameworks. The way of thinking about human decision making as consisting of a series of "phases" has a long intellectual tradition. John Dewey, in his book How We Think (1910), characterizes problem solving as consisting of the following phases: (1) defining the problem, (2) identifying the alternative solutions, and (3) choosing the best one. Graham Wallas, in The Art of Thought (1926), suggests that problem solving proceeds through four steps: (1) preparation, (2) incubation, (3) illumination, and (4) verification. Probably the best-known phase model is the one developed by Herbert Simon (1960), who proposes that the decision-making process consists of three phases: (1) intelligence, (2) design, and (3) choice. In subsequent work he adds a fourth phase, review. Sequence frameworks as a valid description of real-life managerial decision making have been criticized. It has been argued that steplike models of managerial decision making have, erroneously, been inspired by how scientists think. But "scientific thinking is probably a poor model for managerial thinking, yet ... theorists encourage this myth by providing steplike analytical formats. People may resist steplike structures because the procedure they prefer is basically holistic in the sense that all steps are considered simultaneously" (Weick 1983, p. 225 ). Some authors even deny the very existence of decision-making processes on the part of the manager. Decisions accrete and seldom consist in the production of a particular outcome by particular persons (Weiss 1980). Many decisions cannot be pinned down easily in time or place, and the "cerebral rationality of sequential theories" is therefore only a one-sided view of how managers in companies make decisions (Langley et al. 1995). Within each of the ORAC modes, some form of a sequential process could take place. When a decision maker employs the optimizing or reasoning mode, sometimes Simon's stages of intelligence, design, and choice might be discernible. In the analogizing and creating modes, we might observe Wallas's steps of preparation, incubation, illumination, and verification. However, it is unrealistic to consider all marketing decisions as sequential processes. The four modes of the ORAC framework are not stages of a decision process, but rather alternative ways of how a decision maker goes through these stages (if separate stages can be distinguished at all). However, this sequence element is not an essential notion of our ORAC framework. 


\section{Antecedents of MPSMs}

Given that the four MPSMs distinguished here constitute a useful way of classifying different modes of marketing decision making, a natural question is, What are the factors that determine which MPSM will be dominant in a particular decision situation? Our approach to this issue is conceptual. So far no specific empirical research has been carried out on the antecedents of MPSMs. We discuss the factors that, in a first analysis, look the most important in determining which MPSM to adopt, but we do not assume our analysis to be complete or exhaustive. Specifically, we distinguish three sets of antecedents: problem characteristics, decision environment characteristics, and decision-maker characteristics (see Figure 1).

\section{Problem Characteristics}

The most important problem characteristics for determining the MPSM follow:

1. Structuredness (Keen and Scott Morton 1978), which involves the extent to which relevant elements of a problem and the relationships among those elements are known. Structuredness of a problem goes back to Simon's (1960) notion of "programmability." For the optimizing mode, a high level of structuredness is required. Examples of relatively programmable and structured marketing problems are sales management and sales-force decisions and media planning for advertising.

2. Depth of knowledge, which refers to generalized knowledge- that is, the product of scientific research. The optimizing mode requires deep knowledge. However, the required depth of knowledge (in the sense of objective, scientifically verified knowledge) decreases in the direction of reasoning, analogizing, and creating.

3. Availability of data, which is necessary for developing mathematical (optimizing) models. Data also play an important role in the formation of a marketer's mental model, used in the reasoning mode. They help to form an impression of the mechanisms in a market. For analogizing and creating, however, the cognitive processes are more qualitative and subjective.

FIGURE 1

\section{Antecedents of Marketing Problem Solving Modes}

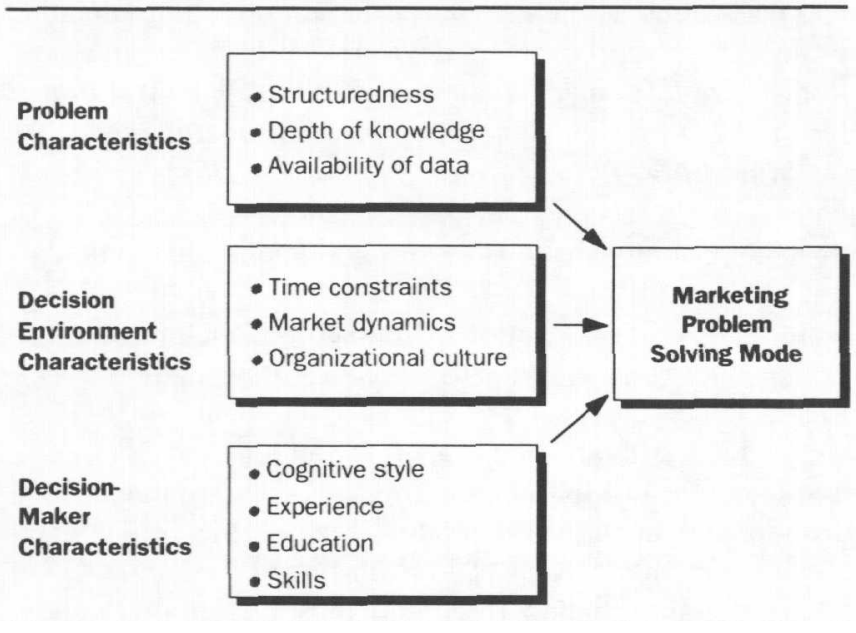

Although there could be tendencies (e.g., advertising decisions often are made by analogizing and creating, whereas distribution decisions often are made by optimizing and reasoning), there is no unequivocal link between the marketing-mix instrument and the MPSM used. The relationship runs through the factors' structuredness, depth of knowledge, and availability of data, which can have different values for the same marketing-mix instrument. A similar argument applies to the use of different MPSMs in different industries. The three problem characteristics distinguished here are not independent. The structuredness of a problem area will increase as the level of knowledge of a domain increases. Furthermore, the availability of data in a particular domain can stimulate scientific research, which in turn will increase the knowledge about the phenomena in that area.

\section{Decision Environment Characteristics}

The following characteristics of the decision environment affect the choice of the MPSM:

1. Time constraints, which often preclude passing through the complete sequence of model building, model estimation, and using the model for optimizing. When time is short, the quickest way to solve a problem is to consult one's memory and search for similar cases experienced before. Time pressure clearly stimulates the analogizing mode. Some amount of reasoning also can occur, but this will be confined to the marketer's consulting of the existing mental model. Time pressure is not conducive to creativity (Hennesey and Amabile 1988; Tardif and Sternberg 1988).

2. Market dynamics. There is a big difference between operating in a stable market and operating in a turbulent one (e.g., compare the current coffee market [Simon 1994] with the market for information technology products). In stable markets mathematical models are more effective. This implies that in stable markets, the optimizing mode will be used more often. Under turbulent market conditions, however, marketers will be hard-pressed to understand and interpret what is going on and constantly will revise their mental models of the market. If mathematical models are feasible at all, they would have to be respecified and reestimated all the time. So in dynamic market conditions we expect that the reasoning mode will be used more often. Turbulence is also conducive to the creating mode (e.g., see the current selection of innovative information technology products).

3. Organizational culture. A company or department will have certain prevailing attitudes and a certain "standard" approach to doing things (Pettigrew 1979). If in a company in general there is a positive attitude toward the use of models and quantitative analyses, this will extend to the way marketing managers go about problem solving in their domain-favoring the optimizing and reasoning modes. Similarly, more heuristic/holistic cultural attitudes favor analogizing and creating.

\section{Decision-Maker Characteristics}

The following characteristics of the decision maker also affect the choice of MPSM:

1. Cognitive style, which refers to the process through which persons perceive and process information. Most common is the classification of decision makers into two categories: analytical and nonanalytical (Bariff and Lusk 1977; Zmud 1979). All other things being equal, analytical decision mak- 
is highly unstructured, which typically would require a creative problem-solving approach, cannot be solved using a mode that assumes more structure.

\section{Positioning of the ORAC Framework}

The ORAC framework presents a classification of the way marketing decision makers solve problems. Although the classification and the particular names of the four MPSMs are new, the development of the ORAC framework is based on conceptual and empirical research that has been carried out in cognitive psychology, cognitive science, decision theory, and management and organizational studies over the past several decades. The ORAC framework proposes that marketing management involves more than just the analytical approach to problem solving. In the psychological literature, two systems of reasoning are distinguished: reasoning through symbol manipulation and reasoning according to the "associative system" (Sloman 1996). (The word reasoning has a broader meaning here than in the sense of our reasoning mode.) Reasoning through symbolic manipulation (called "rule-based system" by Sloman) concentrates on causal, logical, and hierarchical relations and on hard constraints and can be characterized with expressions such as deliberation, explanation, formal analysis, and verification. The associative system of reasoning, conversely, is characterized by parallel processing of information, soft constraints, intuition, creativity, and associative memory. Our optimizing and, to a lesser extent, reasoning modes belong to the symbol-manipulation system, whereas our analogizing and creating modes take place under the associative reasoning system. The ORAC framework extends the perspective of marketing decision making from the analytical/explanatory mode to the associative/creative mode and incorporates the two main systems of human reasoning. Russo and Schoemaker (1990) develop a model for managerial decision making, in which the concept of framing is particularly interesting. Framing means marking the contours of the problem, defining what must be decided, and determining the evaluation criteria. Frames are powerful and determine the decision maker's perspective on a problem; they also constitute boundaries for the solution space. These boundaries are often implicit, because few people are fully aware of the decision frames (mental models) they have adopted (Russo and Schoemaker 1990, p. 20). The optimizing and, to a large extent, the reasoning modes operate within given frames and look for solutions that fit in those frames (convergent thinking). However, it is useful for a decision maker to challenge these frames from time to time and take a different perspective or approach to the problem. Such a process of reframing, which requires divergent and lateral thinking, takes place in the analogizing and creating modes.

In another approach to decision making, decision analysis, a decision tree is constructed, which represents the possible courses of action, and subsequently the subjective probabilities and utilities of the decision maker are measured (Raiffa 1968). The starting point of decision analysis is formulating the problem; beyond that, decision analysis is clearly a case of finding a solution within a given frame (convergent thinking). The purpose of a decision analysis is to find the decision that maximizes the expected subjective utility of the decision maker. Consequently, problem solving through decision analysis is an example of using the optimizing mode. For important marketing decisions, a decision maker might go through the elaborate procedures (see, e.g., Kleinmuntz 1990) of problem structuring, probability assessment, and risk attitude measurement that a decision analysis requires. However, we argue that in day-to-day marketing situations, most problems call for applying one of the other modes.

In the literature on managerial decision making, much attention is devoted to so-called sequence frameworks. The way of thinking about human decision making as consisting of a series of "phases" has a long intellectual tradition. John Dewey, in his book How We Think (1910), characterizes problem solving as consisting of the following phases: (1) defining the problem, (2) identifying the alternative solutions, and (3) choosing the best one. Graham Wallas, in The Art of Thought (1926), suggests that problem solving proceeds through four steps: (1) preparation, (2) incubation, (3) illumination, and (4) verification. Probably the best-known phase model is the one developed by Herbert Simon (1960), who proposes that the decision-making process consists of three phases: (1) intelligence, (2) design, and (3) choice. In subsequent work he adds a fourth phase, review. Sequence frameworks as a valid description of real-life managerial decision making have been criticized. It has been argued that steplike models of managerial decision making have, erroneously, been inspired by how scientists think. But "scientific thinking is probably a poor model for managerial thinking, yet ... theorists encourage this myth by providing steplike analytical formats. People may resist steplike structures because the procedure they prefer is basically holistic in the sense that all steps are considered simultaneously" (Weick 1983, p. 225). Some authors even deny the very existence of decision-making processes on the part of the manager. Decisions accrete and seldom consist in the production of a particular outcome by particular persons (Weiss 1980). Many decisions cannot be pinned down easily in time or place, and the "cerebral rationality of sequential theories" is therefore only a one-sided view of how managers in companies make decisions (Langley et al. 1995). Within each of the ORAC modes, some form of a sequential process could take place. When a decision maker employs the optimizing or reasoning mode, sometimes Simon's stages of intelligence, design, and choice might be discernible. In the analogizing and creating modes, we might observe Wallas's steps of preparation, incubation, illumination, and verification. However, it is unrealistic to consider all marketing decisions as sequential processes. The four modes of the ORAC framework are not stages of a decision process, but rather alternative ways of how a decision maker goes through these stages (if separate stages can be distinguished at all). However, this sequence element is not an essential notion of our ORAC framework. 


\begin{tabular}{|c|c|}
\hline Date of Origin & Main Characteristics \\
\hline Marketing Models 1960 & $\begin{array}{l}\text { - Mathematical representation } \\
\text {-Optimal values for marketing instruments } \\
\text { - Objective } \\
\text {-Best solution }\end{array}$ \\
\hline Marketing Information Systems (MKISs) 1965 & $\begin{array}{l}\text { - Storage and retrieval of data } \\
\text {-Quantitative information } \\
\text { - Registration of "what happens in the market" and "why" } \\
\text { (analysis) } \\
\text {-Passive system }\end{array}$ \\
\hline Marketing Decision Support System (MDSSs) 1980 & $\begin{array}{l}\text {-Flexible systems } \\
\text { - Recognition of managerial judgment } \\
\text { - Facilities to "what-if" questions (simulation) }\end{array}$ \\
\hline Marketing Expert Systems (MESs) 1985 & $\begin{array}{l}\text { - Centers on marketing knowledge } \\
\text {-Human experts } \\
\text { - Rule-based knowledge representation } \\
\text { - Normative approach: best solution }\end{array}$ \\
\hline Marketing Knowledge-Based Systems (MKBSs) 1990 & $\begin{array}{l}\text {-Diversity of methods, including hybrid approaches } \\
\text { - Structured knowledge representation, including frame- } \\
\text { based hierarchies } \\
\text {-Model-based reasoning }\end{array}$ \\
\hline Marketing Case-Based Reasoning Systems (MCBRs) 1995 & $\begin{array}{l}\text {-Similarity with earlier cases } \\
\text { - Storage of cases in memory } \\
\text { - Retrieval and adaptation } \\
\text { - No generalization }\end{array}$ \\
\hline Marketing Neural Nets (MNNs) 1995 & $\begin{array}{l}\text { - Training of associations } \\
\text {-Pattern recognition } \\
\text { - No a priori theory } \\
\text { - Learning }\end{array}$ \\
\hline Marketing Creativity-Enhancement Programs (MCEPs) 2000 & $\begin{array}{l}\text {-Association through connections } \\
\text { - Idea generation } \\
\text { - Endorsement of creativity in problem solving }\end{array}$ \\
\hline
\end{tabular}

tion, "What happened?" The present MKISs also have analytical capabilities for examining the causes of observed phenomena. These can be used to answer "why" questions. Marketing information systems are basically passive systems: They provide information, but it is up to the marketing decision maker to attach conclusions to this information and to decide whether to act on those conclusions. Typically, an MKIS provides data on marketing indicators on a regular basis. For example, each month the marketing research or information systems department sends actual figures to the relevant employees in the company, sometimes different figures to different persons, depending on their responsibilities. Marketing information systems often are tailored to the specific needs of individual companies. An example of an MKIS, used by different companies, is the well-known INF*ACT system developed by Nielsen, which is fed with data from a retail scanning panel.

Marketing decision support sustems (MDSSs) constitute the instantiation of the more general concept of decision support systems (DSSs) in marketing. This concept emerged in the 1970 s and caught on quickly in the manage- ment literature (Keen and Scott Morton 1978; Sprague and Carlson 1982). Compared with classical operations research, which was the main source of inspiration for marketing models, a DSS takes a more practical and flexible approach to problem solving. Its focus is on semistructured, instead of structured, tasks. Its purpose is to support rather than replace managerial judgment and to improve the effectiveness of decision making rather than its efficiency. Little (1979, p. 9) defines an MDSS as "a coordinated collection of data, models, analytical tools and computing power by which an organization gathers information from the environment and turns it into a basis for action." An MDSS makes it possible for marketing managers to model marketing phenomena according to their own ideas (mental models). In that sense an MDSS can be conceived of as a "relaxed" version of the more rigorous marketing models. Conversely, an MDSS also can be seen as an extension of an MKIS. Like an MKIS, it is a combination of information technology, marketing data, and analytical capabilities, but with much more emphasis on the last component. An MDSS contains an explicit model base. Whereas an MKIS 
is particularly geared toward answering "what" questions (what is happening in the market?) and "why" questions (why did it happen?), an MDSS is especially equipped to answer "what if" questions (what will happen if...?). Using its model base, an MDSS can carry out simulations in order to answer such questions. Examples of MDSSs are the ADBUDG system (Little 1970), which predicts market shares for given advertising budgets (an MDSS "avant-lalettre"), and ASSESSOR (Silk and Urban 1978), which predicts the market share of a new product given its attributes and the introduction campaign.

Marketing expert systems (MESs) are MMSSs that emphasize the marketing knowledge component. The systems described so far do use qualitative marketing knowledge in some form-for example, for specifying the marketing variables deemed relevant in a marketing model or for choosing the indicators on which MKISs provide information. However, none of these systems deals with marketing knowledge explicitly. The expert system concept emerged in the field of artificial intelligence in the late 1970s (Feigenbaum, McCorduck, and Nil 1988; Harmon and King 1985). The basic philosophy underlying expert systems is to capture the knowledge from an expert in a specific domain and make that knowledge available in a computer program for solving problems in that domain. The goal of an expert system, therefore, is to replicate the performance levels of a human expert in a computer model (Rangaswamy 1993). An MES for sales promotions, for example, would contain knowledge from an expert on sales promotions. Typically, in an expert system, knowledge is represented in the form of "if-then" rules. For example, "if you want to stimulate trial, then sampling is an appropriate type of sales promotion." Basically, an expert system searches for the "best" solution for a given problem. In this sense it takes a normative approach.

The first MESs appeared in the late 1980s (Burke et al. 1990; Gaul and Both 1990; McCann and Gallagher 1990; Rangaswamy et al. 1989). By 1990 , more than 20 of these MESs were identified (Wierenga 1990). Expert systems are confined to systems that contain knowledge originating from human experts. Expert systems are a subset of knowledge-based systems and involve solving narrowly bounded problems typically solved by human experts (Dutta 1993, p. 11). A representative example of an MES is Dealmaker (McCann and Gallagher 1990), which contains knowledge collected from grocery and drug retailers and can predict the impact of a given deal offer. Another example is ADCAD (Burke et al. 1990), which is an advisory system for advertising copy and execution.

Marketing knowledge-based systems (MKBSs) refer to a broader class of systems than do MESs. In the first place, this applies to the source of the knowledge. In MKBSs the knowledge originates from any source, not just from human experts but also from textbooks, cases, and so on. Second, the set of possibilities to represent knowledge is much richer and not limited to rule-based representation. A fertile alternative approach is knowledge representation in the form of "networks of concepts." This approach shows a direct parallel with the way humans store information in their long-term memory (Dutta 1993; Luger and Stubblefield 1993). Seman- tic networks and frame-based hierarchies are examples of this method of structured knowledge representation. The similarity of structured knowledge modeling with the way humans deal with concepts in their minds makes it easy to represent managers' mental models in MKBSs and use them for "model-based reasoning." Although frame-based technologies only recently have entered the marketing domain (Wierenga 1990), because of their flexibility, frame-based models have the potential to be applied widely in marketing (Rangaswamy 1993, p. 752).

An example of an MKBS using an object-oriented design is the Brand Manager's Assistant (McCann, Lahti, and Hill 1991), which supports brand managers with monitoring, analyzing, and designing tasks related to their brands. When we follow Rangaswamy's straightforward definition of knowledge-based systems-that is, "decision models that use AI [artificial intelligence] methods" (Rangaswamy 1993, p. 750)-all developments in AI have the potential to add new and useful features to MKBSs. Marketing knowledge-based systems do not stand for just one particular approach to dealing with knowledge in marketing but encompass a diverse collection of knowledge representation methods, procedures for reasoning, learning, and problem solving that can be brought to bear to support marketing decision making. At some point a new technology originated from AI can get so substantial that it becomes a field in itself. This has occurred with case-based reasoning (CBR) and neural nets (NNs), which constitute the basis for the two MMSSs that we describe next.

Marketing case-based reasoning systems (MCBRs) are based on the fact that analogical reasoning is a natural way to approach problems and that a lot of marketing management decisions well could take place in the analogizing mode. A critical element, then, is to bring to mind the right cases. If analogizing is such a dominant and fertile problemsolving mode, it is useful to strengthen the "analogizing power" of a decision maker by assisting him or her in reminding. This can be done by making cases available in a case library and providing tools for retrieving and accessing them. This idea is the basis of CBR, which recently has emerged as an important new methodology in AI (Aamodt and Plaza 1994; Kolodner 1993; Riesbeck and Schank 1989). The basic idea of a CBR system is that historical cases are stored with all the relevant data kept intact-that is, in the form of a coherent "chunk." This sometimes is called storage of knowledge in "raw form," which is different from storage in "compiled form" (e.g., rules that an expert has deduced from previous experiences; Riesbeck and Schank 1989). In CBR systems, no generalizations take place. Case-based reasoning for problem solving consists of the following steps. A case as similar as possible to the problem at hand is sought. From this retrieved case, a "ballpark" solution is extracted. This is followed by "adaptation," which is the process of fixing an old solution to a new situation, and "criticism," which is the process of critiquing the new solution before trying it out. Case-based reasoning systems employ indexes for representing cases, search and retrieval algorithms to find the right cases, and procedures for matching, adapting, and transforming cases (Kolodner 1993). 
So far, CBR has been applied to many different types of problems (Dutta 1993; Kolodner 1993). Applications of CBR in marketing have started to appear only recently. Examples are ADDUCE (Burke 1991), which infers how consumers will react to a new advertisement by searching relevant past advertising events and a system that forecasts promotional sales for a given promotion based on historical analogs from a case base (McIntyre, Achabal, and Miller 1993).

Marketing neural nets (MNNS) are applications of a technology in marketing that has become prominent in cognitive science/AI during the past decade and a half (Dutta 1993; Haberlandt 1994; Johnson-Laird 1988; Luger and Stubblefield 1993; Rumelhart, McClelland, and PDP Research Group 1986). Neural nets are used to model the way human beings attach meaning to a set of incoming stimuli-that is, how people recognize patterns from signals. They were inspired by the actual physical process that takes place in the human brain, where incoming signals are transmitted through a massive network of connections, which are formed by links among neurons in the brain (another name for NNs is "connectionism"). Through this network of connected neurons, a human being is able to recognize patterns in sets of incoming stimuli. Through this process, a specific output (e.g., "triangle") is connected to input (e.g., a drawing of a triangle). An artificial $\mathrm{NN}$ can be trained to make the same type of associations between input and output. For example, NNs can be trained to recognize promising oil drilling options from soil data, formulate a diagnosis on the basis of a patient's medical data, and predict whether a company will fail on the basis of financial data (Dutta 1993).

Applying this approach to marketing, an MNN should be able to recognize promising new product opportunities (if properly trained on the relationship between new product characteristics and success on past cases) or distinguish between successful and less successful sales-promotion campaigns. A specific feature of NNs is their ability to learn. Learning occurs constantly because of the examples presented to the network. This way experience automatically is absorbed in the net. Another specific feature of NNs is the complete absence of a priori theory. The network just adapts itself to the data and searches for the best fit between inputs and outputs. This makes NNs more suitable for prediction than for explanation. The first examples of MNNs have appeared recently. The technology has been used to predict television audiences (Fitzsimons, Khabaza, and Shearer 1993), for market segmentation (Mazanec 1993), and for database marketing (Zahavi and Levin 1995).

Marketing creativity-enhancement programs (MCEPS) are computer programs that stimulate and endorse the creativity of a marketing decision maker. (By MCEPs we do not mean programs claimed to be creative themselves, but rather programs that facilitate the creativity of the user.) Creativity research shows that people can be helped to be more creative. The question is whether computers can be instrumental in offering this help (Elam and Mead 1990; Kabanoff and Rossiter 1994). Creativity has not received much attention in DSS research and development so far. However, research is emerging that could increase our understanding of the link between creativity and DSS. This research (Elam and Mead 1990; MacCrimmon and Wagner 1994) suggests that, under certain conditions, the creativity of problem solvers can be enhanced by means of creativity software. It can be expected that this also applies to marketing problem solvers. Marketing creativity-enhancement programs seem to offer promising possibilities. So far, we are only aware of one marketing system that has a "creativity module": The most recent version of the CAAS system for advertising design developed by Kroeber-Riel (1993) performs a creative search of pictorial motifs for emotional advertising.

\section{Summary of MMSSs}

In the right-hand side of Table 1 we summarize the most characteristic features of the MMSSs. Although there might be agreement on the big picture, we could argue about the details of our classification of MMSSs. For example, logically, marketing models and MKISs can be seen as special cases of MDSSs. Also, MESs, MCBRs, and MNNs can be conceived as subclasses of a broader category of MKBSs. However, as we show in Table 1, the systems mentioned have so many characteristics of their own that for determining which MMSS to use for which MPSMs, we treat them separately.

Regarding the whole set of MMSSs, we can make a few comments. The field of MMSSs is dynamic and constantly changing because of developments in the constituent components of MMSSs. Our presentation of MMSSs makes this dynamic character manifest. The dynamics in the field of MMSSs will continue, and in five years the scene certainly will be different from now. These dynamics also are reflected in the fact that the various MMSSs are in different stages with respect to their use and adoption in companies. The first three types of MMSSs-marketing models, MKISs, and MDSSs-are accepted and established by now. To a somewhat lesser extent this is also true for MESs. However, the last four MMSSs-MKBSs, MCBRs, MNNs, and MCEPs - are at this moment emerging technologies. They offer promising opportunities, but their definite contributions remain to be substantiated.

\section{Matching MPSMs and MMSSs}

In the previous sections we discuss the MPSMs of the ORAC framework (the demand side) and the different types of MMSSs (the supply side). In this section we attempt to match the support requirements of the four MPSMs with the capabilities of the various MMSSs to determine which types of MMSSs are appropriate for the different MPSMs.

Dutta, Wierenga, and Dalebout (1997a) define two dimensions as important for the design of management support systems: the object of support and the mode of support. The object of support involves the question, What to support? Three objects of support can be distinguished: outcome, process, and learning. The outcome-oriented view of decision making primarily involves the final decision. The emphasis is on ensuring that the best or "correct" output is produced for the appropriate set of inputs. In the processoriented view, the emphasis is on the process by which decisions are made and not solely on the final outcome. Finally, 
FIGURE 2 Matching MPSMs and MMSSs

\begin{tabular}{|c|c|c|c|}
\hline MPSM & $\begin{array}{l}\text { Object(s) of } \\
\text { Support }\end{array}$ & $\begin{array}{l}\text { Mode of } \\
\text { Support }\end{array}$ & Most Appropriate MMSS(s) \\
\hline Optimizing & Outcome & Automate & $\begin{array}{l}\text { Model } \\
\text { MES }\end{array}$ \\
\hline Reasoning & $\begin{array}{l}\text { Process and } \\
\text { Learning }\end{array}$ & Informate & $\begin{array}{l}\text { MKIS } \\
\text { MDSS } \\
\text { MNN }\end{array}$ \\
\hline Analogizing & $\begin{array}{l}\text { Process and } \\
\text { Learning }\end{array}$ & Stimulate & $\begin{array}{l}\text { CBR } \\
\text { NN }\end{array}$ \\
\hline Creating & Process & Stimulate & MCEP \\
\hline
\end{tabular}

when the object of decision support is learning, the relevant question is how to improve the decision and the decision process. How can the decision maker learn from the decision process so that next time the decision maker can do better? Three modes of support also can be distinguished: automate, informate, and stimulate. Automation of decision making has been the traditional strength of operations research. Management support systems with an emphasis on automation have certain decision procedures and mechanisms "hardwired" in the system. Also, many expert systems have as their primary goal to automate decisions. The term "informate" was first used by Zuboff (1985) to denote the capability of intelligent technology to capture and provide information about organizations. "To informate" has a more active connotation than "to inform": The attention of the decision maker is drawn to specific events. Finally, in the stimulate mode of decision support, the decision maker is aided in finding new solutions by questioning existing frames and norms, noticing special features in the decision environment, making remote associations, and so on.

When we apply the design dimensions object of support and mode of support to the ORAC modes, we arrive at a mapping of MPSMs into their most appropriate MMSSs, as given in Figure 2.

\section{Optimizing}

In the case of optimizing, a best solution exists and the MMSS should ensure that this solution is found. So the emphasis is on the final solution-that is, the outcome of the decision process. In principle, decisions can be automated and left to a computer. The first type of MMSS matching the design requirements of the optimizing mode is marketing models. Marketing models provide a mathematical representation of the marketing problem and are the starting point for finding the objectively best solution for the values of the marketing instruments. Whereas marketing models provide the best quantitative solution, MESs aim at providing the best solution if the problem is described in terms of qualitative relationships among the variables. Under the optimizing mode, a marketing model might be used to determine the advertising budget and, subsequently, an MES might be applied to find out what the copy and the execution of the advertisements should be.

\section{Reasoning}

In the reasoning mode, the object of support for the decision maker should not be so much a particular outcome (a precise recommendation on what to do), but rather the marketing manager's decision-making process. Furthermore, the support of the decision-making process is not limited to the decision at hand, but also should help for decision occasions in the future. The knowledge about the decision domain is constantly developing (dynamic memory). Consequently, the MMSS should enable marketing managers to enhance their knowledge continuously and revise their mental models (especially relevant in turbulent markets). This process is called learning. The basic mode of support in this situation is to informate. Under the reasoning mode, an MMSS should give information about what is going on in the market and should draw a manager's attention actively to significant events. Marketing management support systems can support the reasoning mode in two ways: (1) through the formation and revision of the mental models of managers and (2) through reasoning with those mental models. For the first purpose, information is needed about what happens in the market - that is, actual facts and data (the "what" question). This is the contribution of MKISs. Using its model base, an MDSS can help to achieve a better understanding of the mechanisms in a market by means of simulation (answering "what-if" questions). Marketing neural nets also can help to explore what is going on in a market. An MNN can discover patterns in the interdependencies among marketing variables-for example, capture the characteristics that distinguish successful from unsuccessful new products. Whereas MKIS, MDSS, and MNN are primarily instrumental in the formation of mental models, an MKBS is particularly suited to represent a decision maker's mental model in a computer and reason with this model (model-based reasoning), the second purpose referred to previously. Systems can be built for monitoring and diagnosing market events and suggesting appropriate actions in the same way as the manager would do. An example of such a system is CoverStory (Schmitz, Armstrong, and Little 1990). CoverStory produces short reports and graphs about the most important events in a market (informate) by scanning data. In the era of the "marketing information revolution" (Blattberg, Glazer, and Little 1994), such systems, which take over part of the reasoning from the manager, are indispensable.

\section{Analogizing}

In the analogizing mode, the primary object of support is the process of finding suitable cases and adapting them for the current problem. In the analogizing mode the MMSS should stimulate the decision maker by actively coming up with solutions of earlier cases and proposing transformations of earlier solutions. There is also learning involved, so that future decisions can benefit from current experiences. Marketing case-based reasoning systems are the prime MMSSs that match the requirements of the analogizing mode. The 
development of CBR technology was inspired by the desire to support the analogy-seeking behavior of decision makers. Case-based reasoning systems consist of large sets of cases stored in a computer, with efficient indexing systems for finding the cases that are similar to a problem situation at hand and facilities to transform or adapt earlier solutions to the current situation. For example, a product manager who has to develop a sales promotion for his or her brand can be inspired by an action present in his or her case base that was successful for a similar product in a different market. A CBR system can augment a decision maker's memory by providing access to a large collection of relevant cases. Human decision makers, conversely, are fairly good at adapting cases to the current situation (Dutta, Wierenga, and Dalebout 1997b). Ultimately, some form of generalization takes place in the analogizing mode (learning from experience). For that purpose, MNNs could be used to search for patterns in the cases of the case base.

\section{Creating}

In the creating mode, an MMSS should be directed toward supporting the creative process and should fulfill a stimulating role-that is, generate cues and ideas that trigger the user. Creativity consists to a large extent of making connections and associations between remote concepts. This should be facilitated by an MMSS. As mentioned previously, there is an emerging class of creativity-enhancement programs that match well with the demand for creativity support in the domain of marketing. Research is needed to gain experience in using this approach to solve marketing problems. Pursuing this path will lead to a new type of MMSS-MCEPs.

\section{An Integrating Framework}

Finally, we assemble the various elements (MPSMs and their antecedents and MMSSs and their components) discussed here into an integrating framework (see Figure 3). The interface of MPSMs and MMSSs is the central part of the framework. In Figure 2, as discussed in the last section, we provide, in effect, a close-up view of the interface.

Figure 3 shows that the MPSMs generate a demand for marketing management support. This demand side is driven by certain antecedent factors (i.e., problem characteristics,

FIGURE 3

Integrating Framework of MPSMs and MMSSs

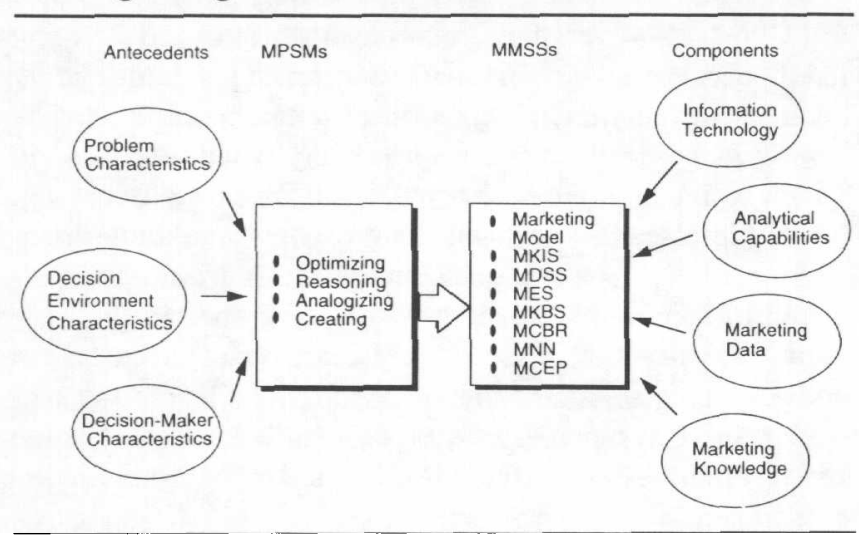

decision environment characteristics, and decision-maker characteristics). The different types of MMSS deliver support with different functionalities. These functionalities result from the capabilities offered by the constituent components (i.e., information technology, analytical capabilities, marketing data, and marketing knowledge).

\section{Other Decision Support Frameworks}

Several authors have developed frameworks to determine the most appropriate decision-making aid. Sprague (1989) tries to relate the required support to the phases of Simon's (1960) model of sequential decision making. However, it proves to be difficult to assign decision aids unequivocally to phases in the decision process. Another approach is to relate the required decision support to the level of decision-for example, strategic planning, managerial control, operational control, and transaction processing (Anthony 1965). The problem with this approach is that at the same level of decision making, decisions with different characteristics can occur. Compare, for example, selecting the cover of a magazine with inventory reordering, which are both decisions at the level of "operational control," but have different decision support requirements.

Gorry and Scott Morton (1971) develop the most prominent framework in the decision support literature that relates decision tasks to needed support. They combine Anthony's (1965) levels of managerial decisions with Simon's (1960) classification of structured, semistructured, and unstructured decisions. This results in a matrix, where for each cell recommendations for appropriate decision support are made. This framework, with some minor extensions, subsequently is used by other authors (e.g., Keen and Scott Morton 1978; Turban 1995). Our framework aims at transforming decision situations, through MPSMs, into requirements for decision support. By doing so, the MMSS that fits best with the decision situation can be determined. Gorry and Scott Morton's distinction between structured and unstructured decisions is also present in our framework, which actually is an extension of their framework in several respects. First, in our framework the structured/ unstructured distinction is only one of the problem characteristics considered as antecedents of the MPSM that determine the most suitable decision aid. Second, our framework explicitly postulates that the characteristics of the problem are, in turn, only one of the groups of factors that determine the MPSM. In addition to the characteristics of the problem, the characteristics of the decision environment and the decision maker also have their impact. Our approach makes it possible to take a much more in-depth view of a particular decision situation and be more precise with respect to decision support recommendations. Consider, for example, a decision situation that involves, in principle, a structured problem. In using the Gorry and Scott Morton framework, one would select an MMSS that would allow for finding an optimal solution. However, time pressure and limited analytical capabilities on the part of the decision maker might make it impractical to conduct an optimizing procedure. In such a case, an MMSS that supports analogizing might be more effective. 


\section{Evolution and Use of MMSSs}

Our integrating framework helps us to understand the evolution and the evolution of the use of MMSSs. The evolution of MMSSs clearly has been supply and technology driven. Developments in the components of MMSSs (given on the right-hand side of Figure 3) are dominant here. In the 1960s and 1970s the major driving forces were developments in the analytical capabilities (e.g., progress in optimization and estimation techniques). During the 1980 s the marketing data component was the driving force (the scanning revolution). At the present time, the developments in the components of marketing knowledge and information technology are predominant, and MMSSs are being equipped with knowledge and intelligence.

The evolution of the use of MMSSs did not follow the supply automatically, however. When marketing models, the first type of MMSSs, were introduced in the 1960s, it was expected that this scientific approach to marketing management problems soon would have a major impact on marketing practice. However, it turned out that marketing managers were not so eager to adopt models: "The big problem with such models is that managers practically never use them" (Little 1970, p. B466). Almost 25 years later, the situation does not seem to be very different: "Even several decades after the earliest operational marketing models were first introduced, their impact on practice remains far below its potential" (Eliashberg and Lilien 1993, p. 19), and "the practical significance of marketing science has remained very limited" (Simon 1994, p. 40). This does not imply that marketing model builders have not been trying hard to develop better systems that actually help managers. Nor have they been oblivious to the importance of managerial judgment for marketing decision making. As early as 1970 , Little introduced "decision calculus," a procedure in which managerial judgment is used for the parameterization of response functions.

Several authors propose reasons to explain the reluctance of marketing managers to use marketing models. These reasons relate to the models as such (e.g., they are not robust enough, not simple enough, or too difficult to understand; Little 1970) to the lack of selling capabilities on the part of the model builder (Lilien 1994) and the lack of relevant data (Simon 1994). However, though such factors might be important, our analysis supposes that a match between the MPSM and the MMSS should exist. Marketing models are an appropriate type of MMSS in the case of the optimizing mode. Given our discussion of the factors conducive to the optimizing mode (e.g., high structuredness of the problem, high degree of knowledge, ample time frame, stable market), it is unlikely that this MPSM will occur frequently. (Even with decision calculus, we remain in the model-building/optimizing mode.) Although developing better models and selling models better will help, this alone will not turn the situation around. We believe that managers will be inclined to use only MMSSs that match with the MPSM they use.

The framework not only helps to understand why certain MMSSs did not catch on or did less well than expected; it also can explain positive developments (Little 1991). For example, the high impact of marketing models on practitioners in the domain of sales management (Lodish 1971; Vandenbosch and Weinberg 1993; see also the Syntex Laboratories case history quoted previously) probably is due to factors like the high level of structuredness of the problem, analytical decision makers, quantitative skills, ample time frame, and a stable market situation. Furthermore, the fact that MKISs are implemented in companies more often than marketing models could be because reasoning occurs more frequently than does optimizing. The ongoing research in marketing (science) will increase our knowledge of marketing phenomena further, which helps to structure marketing problems, thus making them more amenable for optimizing. Many fields are still out there, waiting to be reaped by the analytical power of marketing science. The limited use of marketing models does not imply that marketing science is on the wrong track, as Simon (1994) seems to conclude, or that we need a "paradigm shift." What can be learned from several decades of research in marketing, though, is that progress will not be fast. New knowledge tends to have relatively little impact on improving marketing management practice (Silk 1993). On this count alone, it will take a long time before the majority of marketing problems is solved in the optimizing mode (if this ever happens). For the time being, efforts should be made to develop MMSSs that can support marketing decisions made in the reasoning, analogizing, and creating modes.

\section{Issues for Further Research into MMSSs}

For a demand-side approach to the development of MMSS, more research is needed on how marketing managers actually make decisions and how, in this process, they combine hard data with soft knowledge. In this article, we follow a conceptual approach and develop a framework that can guide the study of marketing managers' decision processes. What we need now is empirical work that gives insight into how different managers go about decision making in different markets, under different circumstances. This calls for an empirical test of our framework.

A first issue would be to determine the conditions under which each of the MPSMs occurs. When and how often can the dominant mode be characterized as optimizing, reasoning, analogizing, or creating? We put forward several "antecedents" of the MPSMs - the characteristics of the problem, of the decision environment, and of the decision maker - and indicated how we believe they affect the choice of MPSM. However, these relationships need further testing in empirical research. The marketing management literature abounds in recommendations on how marketing managers should make decisions. It is surprising to see, in a field in which so much is known about consumer decision making, how little research has been done on how marketing managers actually do make decisions. Next, it would be interesting to take a look at the MMSSs developed in the marketing literature and used (to a greater or lesser extent) in companies. Researchers then can examine whether the success of these systems can be explained by the match (or the lack thereof) between the MMSS and the MPSM, as discussed here. 
Even without exact information about the relative occurrence of the different MPSMs, on the basis of the previous discussion of antecedent factors, our conjecture is that reasoning and analogizing occur often, that creating is also important but has a somewhat lower incidence, and that optimizing probably is applied the least frequently. This would imply (looking at Figure 2) that the object of support most often should be the process of decision making rather than the outcome. This means that we especially need MMSSs that support the decision-making processes of decision makers. Such systems optimally should be geared toward the MPSM employed and could take advantage of the relative strengths and weaknesses of both the decision maker and the computer. In developing such systems, we should realize that managerial thinking and managerial action often cannot be separated. There is a "simultaneity of thought and action," and "thinking is inseparately woven into action" (Weick 1983). A manager seldom sits down for a long period of time contemplating various options for actions. Research should be directed toward systems that present a minimal barrier for use and generate output in the form of suggestions, alternative courses of actions, and warnings that immediately can be "absorbed" into the manager's ongoing stream of thought.

If reasoning and analogizing are important MPSMs, MMSSs also should offer good opportunities for learning (see Figure 2). Generally, the pace of change has stepped up, and many industries are undergoing massive transformations (Prahalad 1995). Marketers continuously must revise their mental models to be able to reason about the everchanging situation, will search for analogies to guide them, and must use their creativity to deal with the dynamics of the situation. Adaptability and response become more important than planning in such situations, and MMSSs should enhance the role of the company as a "market-driven learning organization" (Day and Glazer 1994). An MMSS that not only supports the decision process but also enhances learning can help marketers to adapt their decision processes over time.

A design tradition for MMSSs is lacking, and the field should develop one. Fields such as DSS, engineering, and architecture have a tradition of design (for information systems, machinery, or buildings). To marketing, with its roots mainly in economics and the behavioral sciences, this is an alien phenomenon. For MMSSs, though, the formulation of design principles might be beneficial-and also the development of a common "language" about their dimensions and requirements. We hope we make a contribution in that respect with this article. Many of the existing MMSSs have been developed in an ad hoc way, often driven by some algorithm (e.g., an optimization method) or technology (e.g., expert systems) without first deriving design requirements from the system's intended purpose.

It should be clear from the foregoing discussion that we favor design principles for an MMSS that are demand oriented and take their starting point in the decision-making behavior of marketing managers. So far, a lot of effort has been directed toward MMSSs that support the optimizing mode. As Figure 2 shows, there is also a good supply of MMSSs that can support the reasoning mode. However, for the analogizing and creating modes, the supply of tools still is limited. Data-oriented MMSSs have been developed to a considerable extent, but knowledge-oriented MMSSs are just emerging. Methodologies from AI can help to amplify the knowledge component of MMSSs. The progress in many areas of $\mathrm{Al}$-for example, reasoning, learning, intelligent interfaces, and object-oriented technologies-will enhance our capacity to support marketing decision making. We have seen applications of AI techniques (e.g., expert systems) in the marketing literature, often with the technique playing the leading part and the marketing problem as second fiddle (Wierenga 1990). However, we should not adapt the marketing problem to the AI technology, but rather the opposite. A much more promising approach is to derive the design requirements of the MMSS from the marketing decision situation and then look for the methodologies and tools that have the functionality to realize that design. With this demand and functionality orientation, increasingly we also will see integrated MMSSs-that is, systems that contain components of both data-oriented and knowledge-oriented systems.

We develop a framework of MPSMs, and we define the relationships between MPSMs and the requirements of MMSSs. This produces a new, demand-oriented perspective for the further development of MMSSs. We hope that the concepts, ideas, and frameworks developed here will stimulate further research into the integration of MPSMs and MMSSs.

\section{REFERENCES}

Aamodt, Agnar and Enric Plaza (1994), "Case-Based Reasoning: Foundational Issues, Methodological Variations, and System Approaches," AICOM, 7 (March), 39-59.

Ackoff, Russell L. and Elsa Vergara (1981), "Creativity in Problem Solving and Planning: A Review," European Journal of Operational Research, 7, 1-13.

Amstutz, Arnold E. (1969), "Market-Oriented Management Systems: The Current Status," Journal of Marketing Research, 6 (November), 481-96.

Anderson, John R. (1983), The Architecture of Cognition. Cambridge, MA: Harvard University Press.

Anthony, Robert N. (1965), Planning and Control Systems: A Framework for Analysis. Cambridge, MA: Harvard University Graduate School of Business.
Axelrod, Robert, Ed. (1976), Structure of Decision: The Cognitive Maps of Political Elites. Princeton, NJ: Princeton University Press.

Bariff, Martin L. and Edward J. Lusk (1977), "Cognitive and Personality Tests for the Design of Management Information Systems," Management Science, 23 (April), 820-29.

Bass, Frank M., Robert D. Buzzel, and Mark R. Greene et al., eds. (1961), Mathematical Models and Methods in Marketing. Homewood, IL: Richard D. Irwin. Inc.

Blattberg, Robert C., Rashi Glazer, and John D. C. Little, eds. (1994), The Marketing Information Revolution. Boston: Harvard Business School Press.

Boden, Margaret A. (1991), The Creative Mind: Myths and Mechanisms. New York: Basic Books/HarperCollins. 
(1994), "What Is Creativity?" in Dimensions of Creativity, Margaret A. Boden, ed. Cambridge, MA: Bradford Book MIT Press, 75-117.

Bultez, Alain and Philippe A. Naert (1988), "SH.A.R.P.: Shelf Allocation for Retailers' Profit," Marketing Science, 7 (Summer), $211-31$.

Burke, Raymond R. (1991), "Reasoning with Empirical Marketing Knowledge," International Journal of Research in Marketing, 8 (April), 75-90.

- Arvind Rangaswamy, Jerry Wind, and Jehoshua Eliashberg (1990), "A Knowledge-Based System for Advertising Design," Marketing Science, 9 (Summer), 212-29.

Buzzel, Robert D. (1964), Mathematical Models and Marketing Management. Boston: Harvard University, Division of Research.

Chung, Chen-Hua (1987), "Modeling Creativity for Management Support Via Artificial Intelligence Approaches," in Expert Systems for Business, Barry G. Silverman, ed. Reading, MA: Addi son-Wesley Publishing Company, 363-83.

Courtney, James F., David B. Paradice, and Nassar H. Ata Mohammed (1987), "A Knowledge-Based DSS for Managerial Problem Diagnosis," Decision Sciences, 18, 373-99.

Craik, Kenneth (1943), The Nature of Explanation. Cambridge: Cambridge University Press.

Day, George S. and Rashi Glazer (1994), "Harnessing the Marketing Information Revolution: Toward the Market-Driven Learning Organization," in The Marketing Information Revolution, Robert C. Blattberg, Rashi Glazer, and John D. C. Little, eds. Boston: Harvard Business School Press, 270-88.

Dewey, John (1910), How We Think. New York: D. C. Heath and Company.

Dutta, Soumitra (1993), Knowledge Processing and Applied Artifi cial Intelligence. Oxford: Butterworth-Heinemann.

_- Berend Wierenga, and Arco C. Dalebout (1997a), "An Integrative Perspective on Designing Management Support Systems," Communications of the ACM, (June).

- — a a (1997b), "Case-Based Reasoning Systems: From Automation to Decision-Aiding and Stimulation," IEEE Transactions on Knowledge and Data Engineering, forthcoming.

Elam, Joyce J. and Melissa Mead (1990), "Can Software Influence Creativity?" Information Systems Research, 1 (1), 1-22.

Eliashberg, Jehoshua and Gary L. Lilien, eds. (1993), Handbooks in Operations Research and Management Science, Volume 5. Marketing. Amsterdam: North Holland.

Feigenbaum, Edward, Pamela McCorduck, and H. Penny Nil (1988), The Rise of the Expert Company. New York: Times Books.

Fitzsimons, Mike, Tom Khabaza, and Colin Shearer (1993), "The Application of Rule Induction and Neural Networks for Television Audience Prediction," in Proceedings of the ESOMAREMAC-AFM Symposium Information Based Decision Making in Marketing. Paris: 69-82.

Frank, Ronald E.. Alfred A. Kuehn, and William F. Massy, eds (1962), Quantitative Techniques in Marketing Analyses. Homewood, IL: Richard D. Irwin. Inc.

Gaul, Wolfgang and Martin Both (1990), Computergstutztes Marketing. Berlin: Springer-Verlag.

Gentner, Dedre and Albert L. Stevens, eds. (1983), Mental Models. Hillsdale, NJ: Lawrence Erlbaum Associates

Gorry, G. Anthony and Michael S. Scott Morton (1971), "A Framework for Management Information Systems," Sloan Management Review: 13 (Fall). 55-70.

Haberlandt, Karl (1994), Cognitive Psychology: Boston: Allyn and Bacon.

Harmon. Paul, and David King (1985), Expert Systems. New York: John Wiley \& Sons.
Hennesey, Beth A. and Teresa M. Amabile (1988), "The Condi tions of Creativity," in The Nature of Creativity, Robert J. Sternberg ed. Cambridge: Cambridge University Press, I1-38.

Hoch, Stephen J. and David A. Schkade (1996), "A Psychological Approach to Decision Support Systems," Management Science, 42 (January), 51-64

Hofstadter, Douglas (1995), Fluid Concepts and Creative Analogies: Computer Models of the Fundamental Mechanisms of Thought. New York: Basic Books/HarperCollins.

Holyak, Keith J. and Paul Thagard (1995), Mental Leaps: Analogy in Creative Thought. Cambridge, MA: Bradford BookMIT Press.

Hulbert, James M. (1981), "Descriptive Models of Marketing Decisions," in Marketing Decision Models, Randall L. Schultz and Andris A. Zoltners, eds. New York: Elsevier North Holland.

Johnson-Laird, Philip N. (1988), The Computer and the Mind: An Introduction to Cognitive Science. Cambridge, MA: Harvard University Press.

__ (1989), "Mental Models," in Foundations of Cognitive Science, Michael I. Posner, ed. Cambridge, MA: MIT Press, 470-99.

Kabanoff, Boris and John R. Rossiter (1994), "Recent Developments in Applied Creativity," in International Review of Industrial and Organizational Psychology, Vol. 9, Cary L. Cooper and Ivan T. Robertson, eds. New York: John Wiley \& Sons.

Keen, Peter G. W. and Michael S. Scott Morton (1978), Decision Support Systems: An Organizational Perspective. Reading, MA: Addison-Wesley.

Klayman, Joshua and Paul J. H. Schoemaker (1993), "Thinking About the Future: A Cognitive Perspective," Journal of Forecasting, 12 (February), 161-86.

Kleinmuntz, Benjamin (1990), "Why We Still Use Our Heads Instead of Formulas: Toward an Integrative Approach," Psychological Bulletin, 107 (3), 296-310.

Kolodner, Janet (1993), Case-Based Reasoning. San Mateo, CA: Morgan Kaufmann.

Kotler, Philip (1966), “A Design for the Firm's Marketing Nerve Center," Business Horizons, 9 (Fall), 63-74.

(1971), Marketing Decision Making: A Model Building Approach. New York: Holt, Rinehart and Winston.

Kroeber-Riel, Werner (1993), "Computer-Aided Globalization of Advertising by Expert Systems," in European Advances in Consumer Research, Vol. 1, Gary J. Bamossy and W. Fred van Raaij, eds. Amsterdam: Association of Consumer Research, $110-17$.

Langley, Ann, Henry Mintzberg, Patricia Pitcher, Elizabeth Posada, and Jan Saint-Macary (1995), "Opening Up Decision Making: The View from the Black Stool," Organizational Science, 6 (May/June), 260-79

Lilien, Gary L. (1994), "Marketing Models: Past, Present and Future," in Research Traditions in Marketing, Gilles Laurent, Gary L. Lilien, and Bernard Pras, eds. Boston: Kluwer Academic Publishers.

- and Philip Kotler (1983), Marketing Decision Making: A Model Building Approach. New York: Harper and Row.

___ _ _. - and K. Sridhar Moorthy (1992), Marketing Models. London: Prentice-Hall International.

Little, John D. C. (1970), "Models and Managers, the Concept of a Decision Calculus," Management Science, 16 (April), B466-89.

__ (1975), "BRANDAID: A Marketing Mix Model, Part I Structure: Part 11: Implementation," Operations Research, 23, $628-73$

(1979), "Decision Support Systems for Marketing Managers," Journal of Marketing, 43 (Summer), 9-26.

- (1991), "Operations Research in Industry: New Opportunities in a Changing World," Operations Research, 39 (July/August), 531-42. 
and Leonard M. Lodish (1969), "A Media Planning Calculus," Operations Research, 17 (January/February), I-35.

Lodish, Leonard M. (1971), "CALLPLAN: An Interactive Salesman's Call Planning System," Management Science. 18 (December), 25-40.

- Ellen Curtis, Michael Ness, and M. Kerry Simpson (1988), "Sales Force Sizing and Deployment Using a Decision Calculus Model at Syntex Laboratories," Interfaces, 18 (January/February), 5-20.

Luger, George F. and William A. Stubblefield (1993), Artificial Intelligence: Structures and Strategies for Complex Problem Solving, 2d ed. Redwood City, CA: Benjamin/Cummings.

MacCrimmon, Kenneth R. and Christian Wagner (1994), "Stimulating Ideas Through Creativity Software," Management Sci ence, 40 (November), 1514-32.

Mazanec, Josef A. (1993), "A Priori and A Posteriorie Segmentation: Heading for Unification with Neural Network Modeling," in Proceedings 22nd EMAC Conference, Josep Chías and Joan Sureda, eds. Barcelona: 789-817.

McCann, John M. and John P. Gallagher (1990), Expert Svstems for Scanner Emironments. Boston: Kluwer Academic Publishers.

- William G. Lahti, and Justin Hill (1991), "The Brand Manager's Assistant: A Knowledge-Based System Approach to Brand Management," International Journal of Research in Marketing, 81, 51-73.

McIntyre, Shelby H., Dale D. Achabal, and Christopher M. Miller (1993), "Applying Case-Based Reasoning to Forecasting Retail Sales," Journal of Retailing, 69 (Winter), 372-98.

Pettigrew, Andrew M. (1979), "On Studying Organizational Cultures," Administrative Science Quarterly, 24, 570-8 I.

Prahalad, C. K. (1995), "Weak Signals Versus Strong Paradigms," Journal of Marketing Research, 32 (August), iii-vi.

Raiffa, Howard (1968), Decision Analysis: Introductory Lectures on Choices Under Uncertainty. Reading, MA: Addison-Wesley.

Rangaswamy, Arvind (1993), "Marketing Decision Models: From Linear Programs to Knowledge-Based Systems," in Marketing Handbooks in Operations Research and Management Science, Volume 5: Marketing, Jehoshua Eliashberg and Gary L. Lilien, eds. Amsterdam: North Holland, 733-72.

_ Jehoshua Eliashberg, Raymond R. Burke, and Jerry Wind (1989), "Developing Marketing Expert Systems: An Application to International Negotiations," Journal of Marketing. 53 (October), 24-39.

Ries, Al and Jack Trout (1993), The 22 Immutable Laws of Marketing. London: HarperCollins

Riesbeck, Christopher K. and Roger C. Schank (1989), Inside Case-Based Reasoning. Hillsdale, NJ: Lawrence Erlbaum Associates.

Rumelhart, David E., James L. McClelland, and the PDP Research Group (1986). Parallel Distributed Processing: Explorations in the Microstructure of Cognition, Vols. 1 and 2. Cambridge, MA: MIT Press.

Russo, J. Edward and Paul J. H. Schoemaker (1990), Decision Traps: Ten Barriers to Brilliant Decision-Making and How to Overcome Them. New York: Fireside (Simon and Schuster).

Schmitz, John D., Gordon D. Armstrong, and John D. C. Little (1990), "CoverStory-Automated News Finding in Marketing," Interfaces, 20 (November/December), 29-38

Silk. Alvin J. (1993), "Marketing Science in a Changing Environment," Journal of Marketing Research, 30 (November), 401-04.
- and Glen L. Urban (1978), "Pre-Test-Market Evaluation of New Packaged Goods: A Model and Measurement Methodology," Journal of Marketing Research, 15 (May), 171-91.

Simon, Herbert A. (1960), The Nen' Science of Management Decision. Upper Saddle River, NJ: Prentice-Hall.

—_ (1979), Models of Thought. New Haven, CT: Yale University Press.

Simon, Hermann (1994), "Marketing Science's Pilgrimage to the Ivory Tower," in Research Traditions in Marketing, Gilles Laurent, Gary L. Lilien, and Bernard Pras, eds. Boston: Kluwer Academic Press.

Sloman, Steven A. (1996), "The Empirical Case for Two Systems of Reasoning," Psychological Bulletin, 119 (1), 3-32.

Sprague, Ralph H., Jr. (1989), "A Framework for the Development of Decision Support Systems," in Decision Support Systems, Putting Theory into Practice, Ralph H. Sprague and Hugh J. Watson, eds. Upper Saddle River, NJ: Prentice-Hall, 9-35.

- and Eric D. Carlson (1982), Building Effective Decision Support Systems. Upper Saddle River, NJ: Prentice-Hall.

Sternberg, Robert J. (1977), Intelligence, Information Processing and Analogical Reasoning: The Componential Analysis of Human Abilities. Hillsdale, NJ: Lawrence Erlbaum Associates.

Tardif, Twila Z. and Robert J. Sternberg (1988), "What Do We Know About Creativity?" in The Nature of Creativity: Contemporary Psychological Perspectives, Robert J. Stemberg, ed. Cambridge: Cambridge University Press.

Turban, Efraim (1995), Decision Support Systems and Expert Systems, 4th ed. Upper Saddle River, NJ: Prentice-Hall.

Vandenbosch, Mark B. and Charles B. Weinberg (1993), "Salesforce Operations," in Handbooks in Operations Research and Management Science, Volume 5: Marketing, Jehoshua Eliashberg and Gary L. Lilien, eds. Amsterdam: North Holland. 653-94.

Wallas, Graham (1926), The Art of Thought. New York: Harcourt Brace Jovanovich

Weick, Karl E. (1983), "Managerial Thought in the Context of Action," in The Executive Mind: New Insights on Managerial Thought and Action, S. Srivastava and Associates, eds. San Francisco: Jossey-Bass, 22l-42.

Weiss, Carol H. (1980), "Knowledge Creep and Decision Accretion," Knowledge, I (3), 38!-404

Wertheimer, Max (1959), Productive Thinking. New York: Harpe and Row.

Wierenga, Berend (1990), "The First Generation of Marketing Expert Systems," Working Paper 90-009, Marketing Department, The Wharton School, University of Pennsylvania.

Wiser, Marianne and Susan Carey (1983), "When Heat and Temperature Were One," in Mental Models, Derdre Gentner and Albert L. Stevens, eds. Hillsdale, NJ: Lawrence Erlbaum Associates, 267-98

Zahavi, Jacob and Nissan Levin (1995), "Issues and Problems in Applying Neural Computing to Target Marketing," Journal of Direct Marketing, 9 (Summer). 33-45.

Zmud, Robert W. (1979), "Individual Differences and MIS Success: A Review of the Empirical Literature," Management Sci ence, 25 (October), 966-79

Zuboff, Shoshana (1985), "Automate/Informate: The Two Faces of Intelligent Technology," Organizational Dynamics, (Autumn), $5-18$ 